\title{
Validate the Correlation between Macular Thickness and Temporal Retinal Nerve Fiber Layer Thickness in Normal Eyes with Age and Refractive Status Using Stratus Optical Coherence Tomography
}

Ferdinand Rapthap*, Wewe-u Khalo, Anton De Cruse Waanba, DeepaLamin Khonglah, Banshanhi I Nongkhlaw and Jennifer V Basaiawmoit

Department of Optometry, Bansara Institute of Ophthalmic Sciences, India

Submission: November 16, 2017; Published: December 11, 2017

*Corresponding author: Ferdinand Rapthap, Department of Optometry, Bansara Institute of Ophthalmic Sciences, Shillong, India, Email: ferdinand2013rapthap@gmail.com

\begin{abstract}
Aim: The purpose of this study is to validate the relationship between macular thickness and temporal retinal nerve fiber layer (RNFL) thickness in normal eyes with age and refractive status using Stratus Optical Coherence Tomography (OCT)

Methods: A hospital based cross-sectional study conducted on patients and attendants of Bansara Eye Care Centre, Shillong. Hundred and seven subjects (forty males and sixty seven females) with no major ocular disease or systemic diseases having ocular associations were included for this study. All subjects underwent a comprehensive ophthalmic examination and fundus examination, after the informed consent was taken verbally. Optical coherence tomography (OCT) scans, fast macula and fast RNFL scans, were then performed on both eyes of each individual.

Results: The mean average macular thickness was found to be $237.62 \pm 12.94 \mu \mathrm{m}$, mean RNFL thickness was $101.38 \pm 9.96 \mu \mathrm{m}$ and mean temporal RNFL thickness was $69.34 \pm 11.79 \mu \mathrm{m}$. Macular thickness and temporal RNFL thickness showed a significant difference ( $\mathrm{p}=0.002)$. The average macular thickness showed a significant difference throughout the age group from 15 to 25 years $(\mathrm{p}=0.04)$ and between the age group of 26-35 years $(\mathrm{p}=0.03)$ and those more than 45 years of age $(\mathrm{p}=0.03)$. The center point thickness (CPT), central sub-field (CSF) and average RNFL thickness did not show any significant variation with age ( $p=0.76,0.18$ and 0.32 respectively). No significant difference was found between retinal parameters with refractive status ( $\mathrm{p}=0.83,0.81,0.37$ and 0.56 for CSF, CPT, average macular thickness and RNFL thickness respectively)

Conclusion: Macular thickness and temporal RNFL thickness showed a significant difference. The average macular thickness showed a significant difference in specific age group, whereas the center point thickness (CPT), central sub-field (CSF) and average RNFL thickness did not show any significant variation with age. No significant difference was found between retinal parameters with refractive status.

Keywords: Optical Coherence Tomography (OCT); Macular thickness; Retinal Nerve Fiber Layer (RNFL); Center point thickness (CPT); Central sub- field (CSF); Temporal RNFL
\end{abstract}

\section{Introduction}

Macula is an oval yellowish area in the retina that surrounds the fovea and has the highest visual acuity due to the presence of cones. Many diseases like age-related macular degeneration (ARMD), cystoid macular edema, macular hole and maculopathy etc. could affect the normal morphology or structure of the macula and hence affect vision. The retinal nerve fibre layer (RNFL) is a sensitive retinal structure, formed by the retinal ganglion axons. It is thickest near the optic disc (also known as porusopticus), gradually diminishing toward the oraserrata. Diseases affecting the retinal nerve fibre layer are like glaucoma, peri-papillary atrophy, optic nerve head atrophy, optic neuritis etc.

Ocular diseases involving the macula and retina could lead to irreversible blindness. Therefore, assessment of the macular and RNFL region is an important parameter for staging and monitoring of various diseases, this can be done by the optical coherence tomography (OCT) which is a non-invasive imaging test for the retina [1-5]. Optical coherence tomography (OCT) is a safe and reliable imaging test which uses light waves to take 
cross-sectional scan of the retina and vitreo-retinal interface in micron meter resolution. Images produced by OCT are twodimensional data sets representing the optical backscattering in a cross-sectional plane through the tissue. It enables the non-contact, non-invasive imaging of the anterior part of the eye as well as imaging of morphologic features of the human retina including the fovea and optic disc. It is useful for the identification, detection, localization and quantification of the tissues and serves as an important tool in diagnosing and monitoring various diseases involving the retina because of its reproducibility and reliability [6].

Studies have shown the relationship between the macular and RNFL thickness in diseases such as glaucoma [7], and also changes in the two parameters with age and gender $[8,9]$. The purpose of this study is to look for any relation between the macular thickness and temporal RNFL thickness.

\section{Methods}

This is a cross sectional study conducted in the outpatient department of Bansara Institute of Ophthalmic sciences, Shillong, Meghalaya, India. Hundred and seven subjects including forty males and sixty seven females who underwent complete ophthalmic examination which includes detailed history, visual acuity, extra ocular motility (EOM), refraction (subjective and objective), slit-lamp bio microscopy, intraocular pressure taken with Goldman's applanation tonometer (GAT) and retinal fundus examination was performed after signing the informed consent. OCT scans were then conducted for both macula and RNFL thickness for both eyes of the same individual. Patient with age less than fifteen years of age and those who have history of any ocular diseases and systemic diseases were excluded from the study. Refractive corrections has been converted to spherical equivalent and were considered emmetrope if the spherical equivalent is Plano, Myopia if the spherical equivalent is -0.25 or more and Hyperopia if the spherical equivalent is +0.25 or more based on the subjective acceptance. For this study we used the time-domain Stratus OCT (Carl Zeiss Meditec, Dublin, CA, model 3000 and version 6.0.3). It comprises of $512 \mathrm{~A}$-scans with a single A-scan of 1024 data points, an axial resolution of $<10 \mu \mathrm{m}$ and a scanning acquisition of 1.25 seconds. The macular and RNFL thickness were measured. Four protocols were performed for each eye of every subject in the following order:

\section{Line scan}

It is a scan to acquire a line of different degrees and length. The default line is a horizontal line $\left(0^{\circ}\right)$ with a length of $5 \mathrm{~mm}$. We have used the $90^{\circ}$ and $180^{\circ}$ line scan with a length of $7 \mathrm{~mm}$ for our scan.

\section{Fast macular scan}

It consists of a 6 radial scans centered on the fovea, with each scan formed by 128 single A-scans. The values are displayed in 3 rings- foveal area corresponds to the innermost $1 \mathrm{~mm}$ diameter, the inner ring to $3 \mathrm{~mm}$ diameter and the outer ring to $6 \mathrm{~mm}$ diameter. This scan also gives the macular volume for each eye.

\section{Fast RNFL scan}

A $3.4 \mathrm{~mm}$ circle protocol which consists of 256 individual A-scans in a path around the circumference of a circle of $3.46 \mathrm{~mm}$ in diameter and centred around the optic nerve. It gives the average thickness value for each clock hour and 4 quadrants as well as overall average thickness value for the whole circumference.

\section{Fast optic disc}

This scan protocol gives a topographic map of the optic nerve and cup, giving an optic disc area, cup area, and rim area value. It combines the six optic disc scan into one scan by acquiring six $4 \mathrm{~mm}$ radial line scans in 1.92 seconds of scanning.

All these scans were performed for each individual however, scan of Fast mac and Fast RNFL were considered for the purpose of analysis. The line and fast optic disc scans were done to rule out if any abnormalities were present in the retinal layers or the optic nerve head. Three scans were performed on each eye and the scan with the best signal strength and good centration were taken for analysis. The statistical analysis was done using the SPSS software version 20. Pearson's Correlation was done between right eye and left eye of retinal parameters, Analysis of Variance (ANOVA) for retinal parameters with age and refractive status, Post-hoc Bonferroni correction for retinal parameters with age and refractive status (if significant difference was found), and linear regression analysis was done to find out any association between the retinal parameters. Statistical significance was set to be $\mathrm{p}<0.05$.

\section{Results}

Two hundred and fourteen (214) eyes of one hundred and seven (107) subjects were included in this study, out of which forty subjects were males (37.38\%) and sixty-seven were females $(62.61 \%)$ with the age range between 15 to 88 years with a mean age of $(29.21 \pm 10.76)$.

Distribution of refractive error was analyzed and found $46.72 \%$ were emmetropes, $46.72 \%$ were Myopes and $6.54 \%$ hyperopes.

Mean average macular thickness was $237.62 \pm 12.94 \mu \mathrm{m}$, CPT was $149.94 \pm 18.34 \mu \mathrm{m}, \mathrm{CSF}$ was $181.05 \pm 18.80 \mu \mathrm{m}$, average RNFL thickness was $101.38 \pm 9.96 \mu \mathrm{m}$ and mean temporal RNFL thickness was $69.34 \pm 11.79 \mu \mathrm{m}$ and were given in Table 1 . All the retinal parameters showed a strong positive correlation between the right and left eye of each individual $(r \geq 0.5$, $\mathrm{p}<0.001)$. Therefore, data of right eyes were taken for further statistical analysis (Table 2). 
Table 1: Overall mean values for retinal parameters.

\begin{tabular}{|c|c|c|c|c|c|}
\hline Retinal Parameters & $\begin{array}{c}\text { Average Macular } \\
\text { Thickness }\end{array}$ & $\begin{array}{c}\text { Central Point } \\
\text { Thickness (CPT) }\end{array}$ & $\begin{array}{c}\text { Central Sub-Field } \\
\text { (CSF) }\end{array}$ & $\begin{array}{c}\text { Average RNFL } \\
\text { Thickness }\end{array}$ & $\begin{array}{c}\text { Temporal RNFL } \\
\text { Thickness }\end{array}$ \\
\hline Mean \pm S.D $(\mu \mathrm{m})$ & $237.62 \pm 12.94$ & $149.94 \pm 18.34$ & $181.05 \pm 18.80$ & $101.38 \pm 9.96$ & $69.34 \pm 11.79$ \\
\hline
\end{tabular}

Table 2: Mean and correlation between right and left eyes.

\begin{tabular}{|c|c|c|c|c|}
\hline \multirow{2}{*}{ Retinal parameters } & OD & OS & Pearson's Correlation & \multirow{2}{*}{ p-value p } \\
\cline { 2 - 5 } & Mean \pm S.D $(\boldsymbol{\mu m})$ & Mean \pm S.D $(\boldsymbol{\mu m})$ & $\mathbf{r}$ & $<0.001$ \\
\hline Average macular thickness & $237.62 \pm 12.94$ & $238.68 \pm 13.16$ & 0.939 & $<0.001$ \\
\hline CSF & $181.05 \pm 18.80$ & $181.29 \pm 18.80$ & 0.76 & $<0.001$ \\
\hline CPT & $149.94 \pm 18.34$ & $150.32 \pm 20.38$ & 0.612 & $<0.001$ \\
\hline Average RNFL thickness & $101.38 \pm 9.96$ & $101.66 \pm 9.84$ & 0.82 & $<0.001$ \\
\hline Temporal RNFL thickness & $69.34 \pm 11.79$ & $69 \pm 12.24$ & 0.541 & \\
\hline
\end{tabular}

Both right (OD) and left (OS) eyes showed strong significant positive correlation $(\mathrm{p}<0.001)$ for all. Hence data of OD only are used for further analysis.

The mean values of male and female parameters are given in Table 3. No significant differences was found between males and females in all the retinal parameters by doing unpaired $t$ - test with central point thickness (CPT), central sub field (CSF), Average macular thickness and average retinal nerve fiber layer thickness with $(\mathrm{p}=0.09,0.03,0.24$, and 0.94 respectively). Macular thickness and temporal RNFL thickness showed a significant difference $(\mathrm{p}=0.002)$ (Table 4).

Table 3: Mean of retinal parameters between males and females.

\begin{tabular}{|c|c|c|c|c|}
\hline Retinal parameters & Mean in males $(\boldsymbol{\mu m})$ & $\mathbf{9 5 \%} \mathbf{C I}(\boldsymbol{\mu m})$ & Mean in females $(\boldsymbol{\mu m})$ & $\mathbf{9 5 \%} \mathbf{C I}(\boldsymbol{\mu m})$ \\
\hline Average macular thickness & $240.61 \pm 14.21$ & $235.52-245.68$ & $235.83 \pm 11.86$ & $233.25-238.49$ \\
\hline CSF & $185.80 \pm 16.75$ & $180.14-191.91$ & $178.22 \pm 19.50$ & $173.67-182.90$ \\
\hline CPT & $151.22 \pm 14.26$ & $147.85-156.53$ & $149.17 \pm 20.46$ & $143.74-154.30$ \\
\hline Average RNFL thickness & $99.10 \pm 9.84$ & $96.47-101.96$ & $102.74 \pm 9.85$ & $100.57-105.35$ \\
\hline Temporal RNFL thickness & $68.37 \pm 13.15$ & $64.61-72.45$ & $70.80 \pm 11.78$ & $67.21-74.34$ \\
\hline
\end{tabular}

Table 4: Linear Regression between retinal parameters.

\begin{tabular}{|c|c|c|c|}
\hline Dependent Variable & $\begin{array}{c}\text { Independent variable } \\
\text { Predictors }\end{array}$ & $\mathbf{R}$ & $\mathbf{p}-$ value p \\
\hline Average RNFL thickness & Macular thickness & 0.357 & 0 \\
\hline Macular thickness & Average RNFL thickness & 0.357 & 0 \\
\hline Macular Thickness & Temporal RNFL & 0.299 & 0.002 \\
\hline Temporal RNFL & Macular Thickness & 0.299 & 0.002 \\
\hline
\end{tabular}

Linear regression analysis between the retinal parameters showed a significant difference for all $(\mathrm{p}<0.05)$. The average macular

thickness showed a significant difference throughout the age group from 15 to 25 years $(\mathrm{p}=0.04)$ between the age group of 26-35 years $(\mathrm{p}=0.03)$ and those more than 45 years of age ( $\mathrm{p}$ $=0.03$ ). The centre point thickness (CPT), central sub-field (CSF) and average RNFL thickness did not show any significant variation with age ( $\mathrm{p}=0.76,0.18$ and 0.32 respectively).

The analysis of ANOVA variance between retinal parameters showed a significant difference between average macular thickness and age groups $(\mathrm{p}=0.02)$. However, no variation with age was seen in the Centre point thickness, Central sub field thickness, and average RNFL thickness with $(p=0.76,0.18,0.32$ respectively). Therefore, Posthoc Bonferroni correction was done for the average macular thickness to find the specific variations between the age groups (Table 5). Post HOC Bonferroni shows that the difference is only between group $1(15-26)$ and group 2 (26-35), and between group 2 (26-35) and group 4 ( $\geq 45$ ). No significant difference was found between retinal parameters with refractive status ( $p=0.83,0.81,0.37$ and 0.56 for CSF, CPT, average macular thickness and RNFL thickness respectively). Retinal parameters did not show any difference with refractive status ( $p>0.05$ ) when analyzed using ANOVA Variance

Table 5: Post HOC Bonferroni test to see the significant difference between the age group. 


\section{JOJ Ophthalmology}

\begin{tabular}{|c|c|c|c|c|c|c|c|}
\hline \multicolumn{2}{|c|}{$\begin{array}{c}\text { Bonferroni Analysis } \\
\text { Vependent } \\
\text { Variable }\end{array}$} & (I) agegroup & (J)agegroup & $\begin{array}{c}\text { Mean } \\
\text { Difference (I-J) }\end{array}$ & Std. Error & Sig. & \multicolumn{2}{c|}{$95 \%$ Confidence Interval } \\
\hline $\begin{array}{c}\text { Avgmacula } \\
\text { Thickness }\end{array}$ & 1 & 2 & $-8.44599^{*}$ & 3.06581 & 0.042 & -16.6935 & -0.1984 \\
\hline & & 3 & -1.48395 & 3.64739 & 1 & -11.296 & 8.3281 \\
\hline & & 4 & 3.75838 & 3.74795 & 1 & -6.3242 & 13.841 \\
\hline & 2 & 1 & $8.44599^{*}$ & 3.06581 & 0.042 & 0.1984 & 16.6935 \\
\hline & & 3 & 6.96204 & 4.11321 & 0.561 & -4.1032 & 18.0273 \\
\hline & 3 & 1 & 1.48395 & 3.64739 & 1 & -8.3281 & 11.296 \\
\hline & & 2 & -6.96204 & 4.11321 & 0.561 & -18.0273 & 4.1032 \\
\hline & 4 & 4 & 5.24233 & 4.64397 & 1 & -7.2507 & 17.7354 \\
\hline & & 1 & -3.75838 & 3.74795 & 1 & -13.841 & 6.3242 \\
\hline & & 2 & $-12.20437 *$ & 4.20264 & 0.027 & -23.5102 & -0.8986 \\
\hline & & 3 & -5.24233 & 4.64397 & 1 & -17.7354 & 7.2507 \\
\hline
\end{tabular}

\section{Discussion}

The mean average macular thickness was found to be $237.62 \pm 12.94 \mu \mathrm{m}$, mean RNFL thickness was $101.38 \pm 9.96$ $\mu \mathrm{m}$, mean CPT was $149.94 \pm 18.34 \mu \mathrm{m}$, mean CSF was 181.05 $\pm 18.80 \mu \mathrm{m}$, mean temporal RNFL thickness was $69.34 \pm 11.79$ $\mu \mathrm{m}$. All the retinal parameters between right and left eye showed significant positive correlation $(\mathrm{p}<0.01)$. A study conducted by Lim MC et al. [10] found no variation in the macular thickness with degrees of myopia, similarly with coma. In this study we found no association of RNFL or macular thickness with changes in refractive status ( $p>0.05)$. However the average macular thickness showed a significant difference with increase in age $(p<0.05)$ as found by Wong KS et al. [11] that macular thickness correlated negatively with age in their study.

Age below 15 years of age were not included only subjects above 15 years of age were taken, since it is difficult to obtain cooperation and maintain fixation from most of the pediatric age group. According to a study conducted by Duck JH et al. [12] there was a significant increase in global RNFL thickness with increase in the diabetic macular edema (DME) with a strong correlation, $r=0.576, p<0.001$. Similarly, Oshitari $\mathrm{T}$ et al. [13] in 2009 found that the macular and RNFL thicknesses were altered in early stages of diabetic retinopathy. Linear regression showed that the macular thickness and RNFL thickness parameters showed a significant difference ( $p<0.05$ for all). Hence in this study no association between the macular thickness and average RNFL and temporal RNFL thicknesses were noted or they are interdependent

\section{Conclusion}

From all the retinal parameters had a strong positive correlation between the right and left eyes. The retinal parameters showed no significant relationship with the degree of refractive status but had a specific significant difference between average macular thickness and different age groups. The average
RNFL thickness including temporal RNFL thickness and macular thickness had a significant difference but this association was not strong. Therefore, these parameters can be interdependent on each other even in case of normal subjects. Further analysis of the study is required to understand the association between parameters of RNFL and Macular thickness.

\section{Acknowledgement}

First I thank the God Almighty for His showers of blessings. My sincere word of thanks to Ms. J. SalaiDhavamathi, Assistant Professor, Amity Medical School, Amity University Haryana for giving her time in motivating and helping me in refining my research article. I also thank my family members for their support, encouragement without which this project would not be possible.

\section{Conflict of Interests}

There is no conflict of interest for my study.

\section{References}

1. Budenz DL, Anderson DR, Varma R, Schuman J, Cantor L (2007) Determinants of Normal Retinal Nerve Fiber Layer Thickness Measured by Stratus OCT. Ophthal 14: 1046-1052.

2. Parikh RS, Parikh SR, Sekhar GC, Prabakaran S, Babu JG, et al. (2007) Normal Age Related Decay of Retinal Nerve Fibre Layer Thickness. Ophthalmology 114(5): 921-926.

3. Schweitzer KD, Ehmann D, García R (2009) Nerve fibre layer changes in highly myopic eyes by optical coherence tomography. Can J Ophthalmol 44(3): e13-e16.

4. Chan A, Duker JS, Ko TH, Fujimoto JG, Schuman JS (2006) Normal macular thickness measurements in healthy eyes using stratus optical coherence tomography. Arch Ophthalmol 124(2): 193-198.

5. Eriksson U, Alm A, (2009) Macular thickness decrease with age in normal subjects: a study on the macular thickness map protocol in the Stratus OCT. Br J Ophthalmol 93(11): 1448-1452.

6. Budenz DL, Michael A, Chang RT, McSoley J, Katz J (2005) Sensitivity and specificity of the Stratus OCT for perimetric glaucoma. Ophthalmology 112(1): 3-9. 
7. Ellen H, James H, Leonardo JV, David E Lederer, Joel S Schuman, et al. Analysis of macular volume in normal and glaucomatous eyes using optical coherence tomography. American Journal of Ophthalmology 135(6): 838-843.

8. Won Kyung Song, Sung Chul Lee, Eun Suk Lee, Chan Yun Kim, Sung Soo Kim (2010) Macular Thickness Variations with Sex, Age, and Axial Length in Healthy Subjects: A Spectral Domain-Optical Coherence Tomography Study. IOVS 51: 3913-3918.

9. Badlani V, Shahidi M, Shakoor A, Edward DP, Zelkha R, et al. (2006) Nerve fiber layer thickness in glaucoma patients with asymmetric hemifield visual field loss. J Glaucoma 15(4): 275-280.

10. Lim MC, Hoh ST, Foster PJ, Lim TH, Chew SJ, et al. (2005) Use of optical coherence tomography to assess macular retinal thickness in myopes. Invest Ophthalmol Vis Sci 46(3): 974-978.

This work is licensed under Creative

Commons Attribution 4.0 License

DOI: $10.19080 /$ JOJO.2017.05.555672
11. Song WK, Lee SC, Lee ES, Kim CY, Kim SS (2010) Macular Thickness Variations with Sex, Age, and Axial Length in Healthy Subjects: A Spectral Domain-Optical Coherence Tomography Study. Invest Ophthalmol Vis Sci 51(8): 3913-3918.

12. Hwang DJ, Lee EJ, Lee SY, Park KH, Woo SJ (2014) Effect of diabetic macular edema in the peripapillary retinal nerve fibre layer thickness profile. Invest Ophthalmol Vis Sci 55(7): 4213-4219.

13. Oshitari T, Hanawa K, Adachi Usami E (2009) Changes of macular and RNFL thicknesses measured by Stratus OCT in patients with early stage diabetes. Eye (Lond) 23(4): 884-889.

\section{Your next submission with Juniper Publishers} will reach you the below assets

- Quality Editorial service

- Swift Peer Review

- Reprints availability

- E-prints Service

- Manuscript Podcast for convenient understanding

- Global attainment for your research

- Manuscript accessibility in different formats ( Pdf, E-pub, Full Text, Audio)

- Unceasing customer service

Track the below URL for one-step submission https://juniperpublishers.com/online-submission.php 